\title{
O conceito de Estado para os estudos realistas das relações internacionais: uma análise sobre a obra A politica entre as nações de Hans Morgenthau'
}

\author{
The concept of State for International Relations Studies: an analysis on \\ Politics Among Nations, by Hans Morgenthau
}

Tatiana Berringer

\begin{abstract}
Resumo Este artigo analisa o conceito de Estado utilizado pela corrente realista dos estudos de relações internacionais, abordagem considerada hegemônica nessa área de estudos das ciências sociais, em geral, e da ciência política, em particular. Analisamos como essa categoria foi tratada por Hans Morgenthau, um dos principais autores dessa corrente, na sua obra $A$ política entre as nações. Verificamos uma forte influência do pensamento de Weber, Maquiavel e Hobbes, mas inferimos que Morgenthau não se preocupou em definir claramente o conceito de Estado-nação, e que utilizou concepções divergentes na ciência política - pluralistas e elitistas -, o que leva a uma inconsistência teórica.
\end{abstract}

Palavras-chave Hans Mongenthau; Estado; Nação; Relações Internacionais.

Abstract This article examines the concept of State as it has been used by the realist stream in the international relations studies, approach considered as hegemonic in this area of the Social Sciences, in general, and of the Political Science, in particular. We analyze how this category was treated by Hans Morgenthau, one of the leading authors of this stream, in his book Politics Among Nations. We observe a strong influence of the works of Weber, Maquiavel and Hobbes, but also deduce that Morgenthau was not concerned to stablish a clear definition of the concept of Statenation and that he turned to divergent concepts in the Political Science - pluralists and elitists -, which conducts to a theoretical inconsistency.

Keywords Hans Morgenthau; State; Nation; International Relations.

1 Este artigo foi extraído de minha dissertação de mestrado, defendida em 2011: BERRINGER, Tatiana. Estado e relações internacionais: uma comparação entre Hans Morgenthau e Nicos Poulantzas. Dissertação (Mestrado em Ciência Política). Instituto de Filosofia e Ciências Humanas, Universidade Estadual de Campinas, Campinas, 2011.

a Professora de Relações Internacionais da UFABC. 


\section{INTRODUÇÃO}

Este artigo analisa o conceito de Estado utilizado pela corrente realista dos estudos de relações internacionais, abordagem considerada hegemônica nessa área das ciências sociais, em geral, e da ciência política, em particular. Investigamos como essa categoria foi tratada por Hans Morgenthau, um dos principais autores realistas, ao lado de E. H. Carr e George Kennan. Escolhemos como material de nosso estudo o livro A política entre as nações ${ }^{2}$ publicado em 1948, quando o professor da Chicago University e assessor do Departamento de Estado já vivia nos Estados Unidos (Griffiths, 2004).

De origem alemã e de família judia, Hans Morgenthau tornou-se um refugiado do nazismo alemão, tendo vivido alguns anos na Espanha e a maior parte do tempo nos Estados Unidos. Sob forte influência intelectual de Max Weber, Morgenthau buscava criticar o liberalismo racional e o pensamento kantiano, até então hegemônicos nas relações internacionais. O ponto de partida da filosofia realista desse autor era definir a natureza humana nas suas diferentes dimensões (biológica, racional e espiritual). Ele acreditava que a política subordinava a economia e a religião e era autônoma, pois a questão do poder estaria separada das questões racionais e morais (GRIFFITHS, 2004).

A política entre as nações foi uma tentativa de construção de uma teoria empírica da política internacional, que buscava investigar os padrões recorrentes das ações entre os Estados ao longo da história, tendo como síntese a luta pelo poder. Segundo Morgenthau, a política externa e a política doméstica são distintas em grau, e não em qualidade, devido às realidades e legitimidades adversas no âmbito nacional e internacional dada a existência e a inexistência dos Estados.

Para ele, as relações internacionais são relações de disputas de poder entre os Estados em um ambiente essencialmente anárquico. Como cada unidade soberana busca satisfazer seu interesse nacional e não há uma entidade que detenha o monopólio legítimo da força no sistema internacional - como um Estado mundial - capaz de instaurar a paz e a ordem entre os Estados, permanece a guerra de todos contra todos, que equivaleria ao estado de natureza hobbesiano. Os Estados se encontram frequentemente no preparo de - investindo em armamento e segurança - ou no envolvimento direto em conflitos. Por isso, a guerra é o principal elemento da política internacional, segundo a perspectiva realista.

2 Há seis edições desta obra que foram revisitadas pelo autor ao longo de sua vida, sendo que a sexta e última foi revisada por Kenneth Thompson a partir de textos e artigos deixados em vida por Morgenthau. Essa edição foi publicada em 1980. Utilizamos a tradução da sexta edição de Oswaldo Biato, editada no Brasil em 2003. 
Morgenthau afirma que as atividades econômicas, humanitárias e culturais nem sempre correspondem à política internacional e uma atividade só deve ser caracterizada como política quando corresponder a uma luta por poder, cuja finalidade seria controlar a política de outras nações (Morgenthau, 2003, p. 50). Segundo ele, toda atividade política dispõe de três padrões básicos: aumentar, conservar ou demonstrar poder. Nesse sentido, nas relações internacionais estes padrões correspondem a três políticas internacionais típicas: manutenção do status quo, imperialismo e política de prestígio (Morgenthau, 2003, p. 88), as quais explicitaremos adiante.

Em suma, para o realismo, as relações internacionais são relações entre Estados-nação que se desenvolvem à sombra da guerra e se manifestam através dos canais simbólicos. Esses canais se personificam em duas figuras-chave das relações internacionais: o diplomata e o soldado. A disputa pelo poder entre as nações se limita tanto pela dimensão moral e pelo direito internacional quanto pela balança de equilíbrio de poder entre as nações. Segundo Fred Halliday:

À primeira vista, não é óbvio que existe um problema sobre a definição do Estado nas relações internacionais, pela simples razão de que a distinção operacional é implícita e não convencionalmente sujeita à extensa análise teórica ou empírica. Na verdade, é paradoxal que um conceito tão central à toda a disciplina tenha escapado de uma discussão como esse o fez. Podem ser encontradas muitas discussões sobre a guerra, a soberania, as instituições e assim por diante, mas pode-se procurar em vão nos livros por discussões semelhantes sobre o Estado. Os teóricos das relações internacionais supõem que nós sabemos o que ele é [...]. Assim o "Estado" (Grã-Bretanha, Rússia, América, etc...) abrange em forma conceitual o que é percebido visivelmente no mapa político - o país como um todo e tudo que está dentro dele: o território, o governo, o povo e a sociedade (HALLiday, 1999, p. 91).

Concordamos com a análise de Halliday de que não houve uma preocupação dos estudos teóricos de relações internacionais em definir claramente o conceito de Estado utilizado por esta corrente teórica. ${ }^{3}$ Desconhecemos um trabalho que

3 O único debate que encontramos sobre o Estado e as relações internacionais está na revista Review of International Relations e se intitula: "Forum Introduction - Is the state a person?". Nos artigos, Jackson, Wendt, e Wight discutem se o Estado realmente existe, se é uma construção social, ou uma estrutura. 
sistematize o que os realistas entendem por Estado. ${ }^{4}$ Por isso, buscamos investigar a concepção dessa categoria utilizada nessa obra de Hans Morgenthau.

Em A política entre as nações, o autor realista concebe o Estado e a nação como entidades análogas, expressas pelo termo "Estado-nação”. Na verdade, até mesmo coerentemente com o título da obra, a nação é a categoria fundamental de análise. Neste artigo, investigamos o conceito de Estado-nação utilizado pelo autor e buscamos entender quais as influências teóricas das ciências sociais que influenciaram esse autor na sua definição. Dividimos o presente artigo em duas partes: na primeira, reconstituímos sistematicamente o conceito de Estado e de soberania em Morgenthau, na segunda, tratamos a ideia de nação e dos termos correlatos como poder nacional, identidade nacional, moral nacional e nacionalismo.

\section{MORGENTHAU E O ESTADO}

Em A política entre as nações, importante obra de Hans Morgenthau, a concepção de Estado só é propriamente apresentada no capítulo XXIX, dedicado ao Estado Mundial. Nesta passagem, o Estado-nação é apresentado como ilustração da distinção entre a política doméstica e as relações internacionais. Trata-se da diferença entre uma sociedade governada por leis e por um aparato coercitivo e, de outro lado, uma sociedade anárquica, no sentido da ausência de um poder central. Isto é: para definir as relações internacionais, a descrição do ambiente nacional foi utilizada como padrão comparativo, como fica explícito nas citações abaixo:

As sociedades nacionais devem sua paz e sua ordem à existência de um Estado que, dotado de poder supremo dentro do território nacional, mantém a referida paz e ordem. Essa, aliás, era a doutrina de Hobbes, defensor da ideia de que, sem Estado, as sociedades nacionais se pareceriam com o cenário internacional, e a guerra "de cada homem contra cada homem" constituiria a condição universal da humanidade (Morgenthau, 2003, p. 905).

4 Destacamos que o Estado se mantém enquanto categoria analítica fundamental no neorrealismo, versão renovada do realismo. Segundo Waltz, o principal autor neorrealista, o cenário internacional aproximar-se-ia do modelo metafórico de uma sinuca, na qual os Estados seriam bolas de bilhar, maciças e indivisíveis, colidindo em busca de segurança. Em Man, State, and War, de 1959, o autor apresenta a indivisibilidade como condição de observação dos Estados em meio ao sistema internacional, associando-os a caixas-pretas ou bolas de bilhar. 
A tese se baseia na analogia com as sociedades nacionais. Cabe-nos, portanto, como tarefa inicial, descobrir como a paz e a ordem são mantidas nas sociedades nacionais (MORGENTHAU, 2003, p. 906).

A distinção entre a paz nacional e a instabilidade do cenário internacional deve-se, segundo o autor, ao Estado, que é o fator responsável por manter a paz e a ordem nas sociedades nacionais, de modo que a única forma de salvar o mundo da sua autodestruição seria por meio da instituição de um Estado mundial.

Morgenthau desenvolve o capítulo apresentando melhor a concepção de Estado-nação, que se baseia nas três condições que levam o Estado a manter a paz e a ordem das sociedades nacionais. São elas: o "poder avassalador", as "lealdades supra-seccionais" e a "expectativa de justiça”. Segundo ele, os indivíduos não têm a pretensão e nem a capacidade de romper com a paz nacional por dois motivos: 1) o poder avassalador do Estado coage as tentativas de rompimento com a ordem por parte dos indivíduos; 2) os cidadãos são mais leais à nação do que a qualquer outro grupo no interior da sociedade nacional.

O "poder avassalador" é o que permite que a sociedade preserve a paz dentro do território nacional, pois garante a contenção de qualquer ação que perturbe a paz. Ele se manifesta através do monopólio legítimo da força organizada, tal como Max Weber (1999) define o Estado. Trata-se do poder de coerção e coação (dissuasão). Ou seja, a própria existência do poder do Estado já implica uma pressão social - coação - capaz de dissuadir as perturbações coletivas à organização compulsória daquela sociedade. As ações coletivas são dissuadidas devido à mera existência da força física organizada na sociedade, em outras palavras, o aparato estatal exerce uma pressão orgânica em relação às perturbações coletivas por conta da possibilidade do uso da força para contê-las. A pressão da sociedade para a manutenção da paz no ambiente nacional inibe as transgressões de grupos para com a nação e coloca o desafio aos grupos dissidentes de serem pressionados a construir uma sociedade mais integrada e merecedora de lealdades superiores às daquela sociedade.

De acordo com Morgenthau, o Estado não se mantém apartado dos conflitos intergrupais, pelo contrário, ele está sempre pronto para exterminá-los com o uso da força, uma vez que as disputas de classes, religiões, raças e regiões podem resultar em revoluções, golpes de Estado ou guerras civis que ameaçam a sua própria sobrevivência. A “força avassaladora" se localiza acima dos conflitos entre os grupos de interesse da sociedade e atua conforme a lei visando à paz entre os indivíduos. O Estado atua contra as transgressões para que nenhum indivíduo 
quebre o pacto social firmado entre todos os membros da nação (MorGENTHAU, 2003, p. 913-915). Nesse sentido:

A violência organizada de que dispõem as sociedades nacionais é de certo modo neutra em relação às reivindicações conflitantes dos grupos sociais, na medida em que estes permaneçam dentro dos limites da lei e recorram somente aos meios pacíficos de ação (Morgenthau, 2003, p. 913).

Até esse ponto, como já dissemos, o conceito de Estado apresentado por Morgenthau baseia-se no conceito de Estado moderno de Max Weber. Para ambos, o Estado é uma "relação de dominação de homens sobre homens" (WEBER, 1999, v. 2, p. 526), em que os homens dominados se submetem à autoridade contínua dos dominadores. A obediência dos súditos é condicionada pelo medo - da nação inimiga ou de indivíduos poderosos - ou pela esperança de uma recompensa interesse material ou prestígio social. Weber não definiu os Estados em termos de fins que, segundo ele, têm sido, historicamente, muito variados, mas em termos de meios: o uso da força física e da criação bem sucedida de um monopólio da violência legítima. Segundo o sociólogo:

[...] devemos conceber o Estado contemporâneo como uma comunidade humana que, dentro dos limites de determinado território - a noção de território corresponde a um dos elementos essenciais do Estado -, reivindica o monopólio do uso legítimo da violência física (WEBER, 1972, p. 56).

Nesse sentido, o Estado é uma instituição e uma associação de indivíduos dotada de legitimidade para o uso da força.

Para Morgenthau, "[...] Na realidade, o Estado não passa de outro nome para a organização compulsória da sociedade" (MoRGENTHAU, 2003, p. 915). É uma ordem legal que determina a utilização da força visando à manutenção da paz social. Ao Estado é conferida a capacidade jurídica, legislativa e executiva da nação. Ele dispõe das instituições necessárias para dinamizar e efetivar as leis, a governabilidade e as mudanças sociais.

[...] 1) O Estado propicia a continuidade legal da sociedade nacional, o que permite ao indivíduo sentir a nação como algo contínuo, no tempo e no espaço, como se fosse uma personalidade em cujo nome os homens agem, que exige e recebe serviços e concede benefícios, e em relação ao qual é possível sentir lealdades que 
normalmente são dirigidas somente a poucos outros grupos sociais, com exceção da família e da igreja. 2) O Estado proporciona a maioria dos órgãos institucionais e processa as mudanças sociais. 3) O Estado dispõe dos órgãos necessários para a implementação compulsória de suas leis (MoRGENTHAU, 2003, p. 916).

Para esse autor realista, as lealdades supranacionais estão ligadas ao fato de que as comunidades nacionais, apesar de serem compostas por uma pluralidade de grupos sociais, alguns inclusive antagônicos entre si, unificam-se pelo sentimento nacional, caracterizado como lealdades suprasseccionais. Pois, mesmo que as demandas de um grupo de interesse oponham e excluam a efetivação das demandas do grupo adversário, os cidadãos são convencidos de que a nação é superior a esses conflitos. As entidades nacionais estão, portanto, acima das demais categorias grupais: econômicas, religiosas e partidárias.

Na verdade, segundo o autor, as divergências entre os grupos são atenuadas devido ao fato de que um mesmo indivíduo que participa de vários grupos e deve lealdade a todos não pode destruir um adversário de um grupo $\mathrm{X}$ que seja seu companheiro em outro grupo Y. Por exemplo, A pode ser inimigo de B economicamente, mas ambos podem pertencer à mesma comunidade religiosa ou política, entrecruzamento entre indivíduos e grupos no interior da sociedade nacional que implica em uma redução dos conflitos sociais. Segundo Morgenthau (2003, p. 909):

[...] A e B não são apenas membros de grupos econômicos que se opõem, nem têm somente filiações políticas idênticas, para não falarmos de todos os demais agrupamentos sociais a que pertençam como ainda, por definição, são igualmente membros da mesma sociedade nacional. Compartilham a mesma língua, os mesmos costumes, as mesmas reminiscências históricas, a mesma filosofia social e política fundamental, os mesmos símbolos nacionais. Eles leem os mesmos jornais, ouvem os mesmos programas radiofônicos, obedecem aos mesmos feriados e cultuam os mesmos heróis. Acima de tudo, eles comparam a sua própria nação com as demais e desse modo passam a compreender que têm muito mais em comum entre si do que com os membros dos outros países.

Na interpretação desse autor, portanto, os vínculos nacionais representam para os indivíduos de uma mesma comunidade nacional muito mais do que as divergências entre os grupos sociais; o pertencimento à comunidade nacional faz como que seus membros mantenham autorrespeito entre si. Apesar dos constantes conflitos, os indivíduos evitam medidas que ameacem a coesão interna do país, limitam-se 
aos meios permitidos pela comunidade nacional. Desta forma, a lealdade à nação torna-se um compromisso incontestável para todos os cidadãos, pois estes acreditam que a lealdade para com a nação resulta em benefícios incalculáveis para todos. Os indivíduos confiam ao Estado a capacidade política e o poder supremo para que este instaure a ordem e a paz dentro do território nacional e também a proteja do inimigo externo. O perigo do inimigo externo é fonte de temor de todos os indivíduos e, por isso, não permite nenhuma forma de ação que possa ameaçar a soberania nacional (MORGENTHAU, 2003, p. 907-911).

[...] Somente permanecendo fiel à nação, apegando-se a ela como se fora o manancial de todos os bens terrestres e identificando-se completamente com ela, é que alguém poderá experimentar em si próprio a segurança de pertencer a uma comunidade, a exaltação do orgulho nacional, os triunfos da Pátria na competição com as demais nações. Essa proteção contra a ameaça de destruição vinda do exterior e contra o impulso de ruptura, que pode surgir no seio da comunidade, constitui a preocupação constante de todos os indivíduos. Do mesmo modo, a lealdade para com a nação representa o engajamento supremo de todos os cidadãos. Nada que possa representar uma ameaça à integridade da nação deverá ser tolerado. Quaisquer interesses, ideias e lealdades que possam não ser compatíveis com a preocupação pela unidade da nação têm de ser relegados a um segundo plano de prioridades (Morgenthau, 2003, p. 910).

A expectativa de justiça está ligada à crença de que as reivindicações sociais, mesmo sendo contraditórias, têm a possibilidade de serem parcialmente satisfeitas ou ao menos escutadas pelos representantes políticos. Ou seja, todos os grupos podem submeter seus reclamos à política nacional através da opinião pública, das eleições, dos conselhos ou quaisquer outros mecanismos. A expectativa de justiça contempla dois níveis articulados: os princípios gerais da nação e os interesses dos grupos particulares. Em relação aos interesses gerais da nação, a expectativa diz respeito às questões que correspondem ao bem comum da sociedade-democracia, justiça, igualdade, liberdade e paz social. No entanto, estes mesmos princípios com os quais todos concordam podem tornar-se fontes de conflitos entre grupos descontentes. Portanto, a sociedade deve garantir a voz aos grupos particulares, todos os grupos devem contar com a oportunidade de acesso à justiça. Ou seja, os grupos devem utilizar os mecanismos pacíficos a fim de serem ouvidos e reconhecidos pela sociedade (MorgenthaU, 2003, p. 911-913). 
É nesse ponto que entra em jogo o complexo mecanismo de transformação social, que reconhece a todos os grupos uma oportunidade de submeter as suas reivindicações de justiça à arbitragem da opinião pública, das eleições, das votações parlamentares, de conselhos revisores e mecanismos similares. [...] Tais mecanismos guiam os pleitos conflitantes dos grupos sociais, por meio de canais pacíficos, dando-lhes a oportunidade de serem ouvidos e de disputarem com os seus concorrentes o reconhecimento da sociedade, dentro das normas que sujeitam a todos (Morgenthau, 2003, p. 912-913).

Em suma, até aqui, para Morgenthau, o Estado é o aparato coercivo capaz de destruir o estado de natureza, onde reina a luta de todos contra todos, e instituir a paz e a ordem dentro das fronteiras nacionais, tal como defende Hobbes. O Estado é a concretização do poder central, soberano, e é através dele que a comunidade nacional atua internacionalmente. O Leviatã - o Estado - se coloca acima dos diferentes grupos sociais que conservam interesses antagônicos (MorgENTHAU, 2003, p. 917).

O conceito de Estado utilizado por Morgenthau diferencia-se, segundo ele, tanto da doutrina liberal do século XIX, quanto do marxismo. Segundo o autor realista, para a doutrina liberal a violência organizada da sociedade era completamente neutra, e para o marxismo é uma ferramenta com a qual a classe dominante mantém o seu domínio sobre as classes exploradas. Para Morgenthau, o emprego da força estatal não é completamente neutro, pois o Estado preocupa-se em favorecer o status quo sob o qual emergiu.

[...] A doutrina liberal do século XIX mantinha que a violência organizada da sociedade era completamente neutra, pairando acima do turbilhão de interesses conflitantes, sempre apta a implementar a lei contra quem quer que a violasse. Contra essa doutrina, o marxismo sustenta que a violência organizada da sociedade nada mais é do que a arma com a qual as classes governantes mantêm o seu domínio sobre as massas exploradas. Na realidade, a organização compulsória da sociedade não pode ser completamente neutra, uma vez que, como já vimos, não é totalmente neutra a ordem legal que ela implementa, nem pode deixar de favorecer o status quo ao qual ela deve a sua existência. Uma vez desafiado, o status quo pode contar com o apoio da organização compulsória da sociedade (Morgenthau, 2003, p. 913-914). 
De acordo com o autor, “[...] o poder do Estado é essencial, mas não suficiente, para manter a paz das sociedades nacionais" (Morgenthau, 2003, p. 918). A prova de tal insuficiência seria o elevado número de guerras civis. Segundo o autor, no período de 1480 a 1941, 28\% dos conflitos foram guerras civis, como a Guerra das Rosas na Grã-Bretanha, a Guerra dos Trinta anos na Alemanha, a Rebelião de Taipung na China, entre outras. Tendo em vista tal realidade, Morgenthau acaba por dispensar o conceito de Estado de Hobbes, para quem há uma separação entre sociedade e Estado, metaforizada na ideia do Leviatã. Vejamos um trecho do autor:

A frequência e o poder destruidor dos conflitos civis demonstram que a existência do Estado não assegura automaticamente a preservação da paz doméstica, e a razão disto reside na própria natureza do Estado. O Estado não resulta da criação artificial de uma convenção constitucional, concebida sobre a imagem de alguns princípios abstratos de governo, e que seja suscetível de ser sobreposta a qualquer sociedade que possa existir. Pelo contrário, Estado é parte integrante da sociedade de que ele se formou, motivo por que ele prospera ou decai, na medida em que essa sociedade progride ou degenera. O Estado, longe de ser separado da sociedade, é criado pela sociedade (MorgentHAU, 2003, p. 918-919).

Encontramos mais reflexões sobre a concepção de Estado de Morgenthau em outros capítulos e trechos de A política entre as nações, como a discussão sobre soberania e sobre o poder nacional. Segundo ele, o Estado emergiu a partir do estabelecimento da fronteira territorial nos meados do século XVI. Com ele, deu-se a centralização do poder e da autoridade legislativa. Para esta tese, a teoria legal da soberania solapou a teoria do Estado medieval e delegou o poder de direito e de fato ao monarca. O príncipe ou o monarca suplantaram o papel de autoridade do imperador, do papa e dos senhores feudais. A centralização do poder no soberano tornou-se superior a quaisquer outras forças no interior do território nacional, e os indivíduos passaram a ver no poder real a única fonte de poder com capacidade legislativa e administrativa. Nesse contexto, os demais reis se viram impedidos de exercer funções políticas nos territórios alheios, exceto quando o rei local os permitisse agir politicamente dentro do seu território ou em caso de vitória de guerra. ${ }^{5}$

5 Vale a pena dizer que Morgenthau dedica um capítulo para a definição de soberania e este conceito não é tratado como padrão comparativo entre o ambiente doméstico e o ambiente internacional. 
A soberania caracteriza a nação, em termos legais, como a recipientária da lealdade extrema do indivíduo, como a força social mais forte, como a autoridade suprema que edita e faz cumprir as leis para o cidadão individual (MorgENTHAU, 2003, p. 604).

A doutrina da soberania [...] concedeu ao Estado democrático nacional, com a concepção da soberania popular, uma poderosa arma política (MoRGENTHAU, 2003, p. 568).

Mas a soberania também garante ao Estado autonomia frente ao direito internacional. Neste, as regras são criadas a partir de um consenso entre os Estados, e as leis são compulsórias somente às nações que as consentiram. O direito internacional torna-se ambíguo por reconhecer a soberania estatal, fazendo com que o Estado não reconheça uma autoridade legislativa superior a ele. Da mesma forma, delega autoridade suprema judiciária e executiva a qual se manifesta na "impenetrabilidade" da nação, ou seja, nenhum outro Estado pode realizar atos governamentais naquele território, assim como nenhum Estado pode obrigar um país a se submeter a um processo judicial ou a um tribunal internacional. A soberania estatal pressupõe um direito internacional que corresponda a uma ordem fraca e descentralizada.

Para Morgenthau, a soberania é condicionada pela preexistência de um sistema múltiplo de Estados-nação. Ele considera que há três princípios fundamentais do direito internacional que equivalem a ela: independência, igualdade e unanimidade. Para o autor, independência significa que não há autoridade acima do Estado, fica delegado a cada nação definir os seus assuntos internos e externos, salvo naqueles domínios limitados por tratado ou pelo próprio direito internacional. Portanto, todas as nações devem respeitar este direito. A igualdade remete à ideia de insubordinação entre as entidades nacionais, sendo que entre os Estados independentes não há relação hierárquica entre elas. A unanimidade diz respeito à função legislativa, as nações são iguais independentemente do poder, tamanho e população para votarem e se manifestarem nos colegiados internacionais e na elaboração de normas e tratados entre os Estados.

A soberania é uma autoridade suprema, portanto, indivisível. Não se pode confundir soberania com independência política, militar, econômica e tecnológica. Segundo a concepção de Hans Morgenthau, o Panamá é uma nação soberana da mesma forma que os Estados Unidos, pois a desigualdade e a dependência entre os Estados não têm relevância para a soberania legal das nações. É quase impossível 
que as nações dependentes executem políticas externas e domésticas independentes, contudo, isso não afeta a sua capacidade de legislação e de aplicação das leis no território nacional (Morgenthau, 2003, p. 576-577).

Morgenthau considera, portanto, que a organização da sociedade internacional em Estados-nação é um produto da história, de maneira que pode vir a ser substituída por novas formas. Quando o Estado é incapaz de garantir a sobrevivência da nação, ou a coesão da comunidade nacional, as sociedades nacionais se desintegram e formam outras unidades.

[...] a conexão contemporânea entre o interesse e a nação constitui um produto da história, motivo por que está destinado a desaparecer no curso da mesma história. Nada na posição realista, invalida a presunção de que a presente divisão do mundo político em estados-nação será um dia substituído por unidades de maiores dimensões de natureza muito diferentes e mais consentâneas com as potencialidades técnicas e exigências morais do mundo contemporâneo (MoRGENTHAU, 2003, p. 19).

Segundo o autor, a bipolaridade de poder entre os Estados Unidos e a União Soviética durante a Guerra Fria resultou em uma extrema desigualdade entre estes Estados-potência e os demais Estados, que orbitaram em suas áreas de influência, de tal maneira que a igualdade de soberania entre os Estados se viu solapada. Os Estados fracos se tornaram simples microestados que orbitam em torno dos dois gigantes. A sentença abaixo citada explicita esta análise:

No plano internacional não seria exagero dizer que a própria estrutura das relações internacionais - tal como refletida em instituições políticas, procedimentos diplomáticos e ajustes legais - vem tendendo a distanciar-se da realidade da política internacional e tornar-se irrelevante para a mesma (MORGENTHAU, 2003, p. 12).

Ou seja, a estrutura legal e institucional que pressupõe a existência de múltiplos Estados-nação soberanos já não corresponde mais à ordem internacional, que agora é permeada pela interdependência entre as nações:

A moderna circunstância da interdependência, exige uma ordem política que tome tal fato em consideração, enquanto que, na realidade, a superestrutura legal e institucional de olhos no século XIX, ainda presume a existência de uma 
multiplicidade de estados-nação autossuficientes, estanques e soberanos (MoRGENTHAU, 2003, p. 12).

Nesse ponto vemos que Morgenthau se aproxima das teses nas quais houve uma alteração do papel do Estado, dada as mudanças estruturais dos anos 1970 e 1980. Isso fica ainda mais explícito quando ele discorre sobre a questão nacional e o "universalismo nacionalista", conforme veremos a seguir. No próximo item reconstruímos o que o autor entende por nação e os termos correlatos a essa ideia como moral nacional, interesse nacional, etc. Nosso objetivo foi entender se Estado-nação era um binômio com equivalência ou complementariedade categórica e como a ideia de nação foi apresentada pelo realismo nos estudos teóricos de relações internacionais.

\section{MORGENTHAU E A NAÇÃO}

Para Morgenthau, a nação constrói um sentimento de lealdade superior às que possam existir nela com qualquer outra força. $O$ indivíduo sente-se parte da nação em função da identidade nacional, que institui a ligação do indivíduo com o poder da nação no cenário internacional. Desse modo, o cidadão passou a sentir o poder nacional como algo que lhe pertencesse. Não há uma vontade dos indivíduos de quebrarem a paz nacional, pois conferem à nação uma lealdade superior em relação aos demais grupos sociais.

Como vimos, para Morgenthau, os cidadãos compartilham símbolos e identidades nacionais - língua, costumes, história, bandeira, culto a heróis, feriados - que estão acima das identidades dos grupos econômicos, políticos e religiosos. A identidade nacional envolve os membros da comunidade nacional e cria a percepção de que há elementos que os unifica nacionalmente quando comparado a outras nações. Com isso, identificam o estrangeiro como “o outro”, que além de se encontrar fora das fronteiras nacionais, dispõe de diferentes características simbólicas e políticas. Por isso, o sentimento nacional influencia o pensamento e a ação de cada cidadão criando laços entre os compatriotas e a sensação de pertencimento a esta comunidade nacional, bem como transfere a cada membro, além da sensação de segurança, o sentimento de poder. Os indivíduos se sentem partícipes e dotados do poder que o Estado demonstra diante das demais nações.

Uma nação como tal não é, obviamente, uma coisa empírica. Uma nação como tal não pode ser vista. O que pode ser observado de um modo empírico são exclusivamente os indivíduos que formam uma nação. Isto é o que nos permite dizer 
que uma nação é uma abstração de uma quantidade de indivíduos que dispõem de certas características em comum, e que são essas características que os transformam em membros da mesma nação. Além de ser membro de uma nação e de pensar, sentir e agir dentro dessa condição, o indivíduo pode pertencer a uma igreja, a uma classe econômica e social, a um partido político ou a uma família, e pode, assim, pensar, sentir e agir como integrante dessas mesmas categorias. [...] Assim sendo, quando falamos em termos empíricos do poder político ou da política externa de uma determinada nação, só poderemos estar designando o poder ou a política externa de certos indivíduos que pertencem à mesma nação (Morgenthau, 2003, p. 199-200).

Para Morgenthau, a emergência da nação, tal qual descrita acima, se deu a partir do século XIX, com as guerras napoleônicas. O nacionalismo suplantou as relações de coletividade estabelecidas no passado: sanguíneas, religiosas ou de lealdade ao senhor feudal. Pois antes das guerras napoleônicas somente alguns grupos se identificavam com a política externa de seu país, a qual não era uma política nacional e sim uma política de natureza monárquica. $\mathrm{O}$ nacionalismo moderno envolveu as massas, principalmente as classes trabalhadoras, nas políticas externas e nas guerras nacionais.

Até a Primeira Guerra Mundial, não se poderia falar em identificação de toda a população com o poder e a política dos seus Estados. Neste conflito, até mesmo os partidos socialistas europeus declararam apoio à guerra.

As forças supranacionais, tais como as religiões universais, o humanitarismo, o cosmopolitismo e todos os demais vínculos pessoais, instituições e organizações que congregam os indivíduos dentro de limites nacionais, são hoje infinitamente mais fracas que as forças que vinculam os povos dentro de uma determinada fronteira nacional e os separam do resto da humanidade (Morgenthau, 2003, p. 604).

Há uma predominância da moral nacional, que é o que motiva as ações dos homens no cenário internacional. O indivíduo, por exemplo, recua diante da moral universal de respeito à vida quando pensa em matar um adversário da sua nação, acredita que, com isso, está cumprindo a sua missão de resguardar os interesses nacionais do seu Estado.

Para Morgenthau, os movimentos nacionais tradicionais do século XIX correspondiam: 1) aos conflitos entre uma nacionalidade e o domínio estrangeiro, 
ou melhor, a luta das nações oprimidas pela independência e a constituição de um Estado próprio; ${ }^{6}$ 2) e aos conflitos nacionais entre distintas potências sobre a colonização das demais nações.

Já no século XX, o objetivo do nacionalismo teria sido alterado, resultando no que ele denominou de "universalismo nacionalista". Na Guerra Fria, o capitalismo e o socialismo teriam se tornado as bússolas pelas quais as superpotências definiam e legitimavam suas ações. Logo, a busca de padrões e costumes de uma nação pelas demais nações que integravam o bloco de países de acordo com a divisão bipolar do sistema internacional teria permitido que o nacionalismo se convertesse em uma religião secular, cuja missão seria a salvação da humanidade. É como se as sociedades nacionais de outros Estados passassem a ser fiéis e a se sentirem parte da nação e do poderio norte-americano ou soviético. Com isso, agregou-se aos instrumentos da política externa, além da diplomacia e da força militar, a propaganda psicológica, a partir das quais os Estados-potência buscariam promover seus interesses.

Para Morgenthau, a competição entre as duas filosofias políticas e entre seus respectivos sistemas econômicos e sociais teria tornado o prestígio o principal instrumento da política externa de cada potência. A guerra política entre Estados Unidos e União Soviética requeria a propaganda política para destruir o seu inimigo. A ajuda externa do Plano Marshall e o Comecon (Conselho para Assistência Econômica Mútua) demonstrava a superioridade econômica e tecnológica das duas potências antagônicas.

Com isso, o autor assume que há relação entre a política doméstica e a política externa gerada pelo papel que a propaganda política passou a exercer na política externa dos Estados, pois "o resultado de uma eleição ou de uma guerra civil poderia determinar o curso futuro da política externa de um país" (MorgEnTHAU, 2003, p. 609). Durante a Guerra Fria, a vitória eleitoral de um partido comunista levaria aquele Estado a se alinhar à União Soviética, assim como o contrário levaria o país a se alinhar aos Estados Unidos ou a manter-se neutro.

\footnotetext{
Enquanto o nacionalismo (do século XIX, T.B) quer uma nação em um Estado e nada mais, o universalismo nacionalista de nossa era reivindica para uma nação e um Estado o direito de impor as suas próprias avaliações e padrões de ação sobre todas as outras nações (Morgenthau, 2003, p. 606).
}

6 É importante lembrar que após a Segunda Guerra Mundial, em meados do século XX, muitas nações da Ásia e da África se tornaram Estados independentes. Então, para além das disputas entre as superpotências, o nacionalismo ainda correspondia ao nacionalismo de nação oprimida. 
Para o pensamento realista, o poder político é o meio para alcançar os objetivos da nação e o interesse nacional diz respeito à luta pelo poder entre as nações. Segundo Morgenthau, poder não se refere ao poder cultural ou ao poder do homem sobre a natureza. É o “[...] controle do homem sobre as mentes e ações de outros homens" (Morgenthau, 2003, p. 199), mais especificamente, o controle das autoridades públicas e entre elas e o povo. A relação de dominação existe quando os dominados se submetem à obediência em função da expectativa de benefícios, do receio de desvantagens e do respeito ou amor aos indivíduos e instituições. A dominação pode ser exercitada por meio de ordens, ameaças, autoridade ou carisma (Morgenthau, 2003, p. 51-52). Pois, “[...] a tendência a dominar constitui um componente de todas as associações humanas, desde a família, passando pelas associações estudantis e profissionais e pelas organizações políticas locais, até o Estado" (Morgenthau, 2003, p. 64). Em todos os agrupamentos políticos, e principalmente nas nações, a vida política é uma disputa contínua pelo poder. Nas eleições, nas assembleias legislativas, nos tribunais e na administração, os homens procuram manter o poder sobre outros homens. ${ }^{7}$

Poder político não equivale à força, apesar da força militar ser o maior elemento de poder de uma nação. É verdade também que a utilização da força ou quaisquer outros instrumentos de poder demonstram que a nação carece de prestígio e carisma. Na guerra, o poder político é substituído pelo militar. Por isso, os preparativos militares devem sobrepor-se ao uso efetivo das armas e, com isso, dissuadir as demais nações, tornando assim desnecessária a utilização da força. "No campo da política internacional, a força armada, como ameaça ou potencialidade, representa o fator material mais importante na construção do poder político de uma nação" (Morgenthau, 2003, p. 52).

Cabe mencionar, no entanto, que, segundo Morgenthau, o poder da política externa de um Estado não corresponde efetivamente ao poder de todos os indivíduos da nação. Para ele, o poder nacional é exercido e conduzido por um pequeno

7 Para a definição de poder, Morgenthau resgata, entre outros, Max Weber. Toda a influência de Weber no pensamento morgenthaliano não é explicita em A política entre as nações. Apesar de Weber ser a sua principal fonte, Morgenthau só utiliza uma citação do sociólogo. Segundo Morgenthau, o realismo parte do conceito-chave de interesse definido como poder, para ele o poder é a essência da política. Ele resgata a célebre frase de Tucídides: "a identidade de interesses é o mais seguro dos vínculos, seja entre Estados, seja entre indivíduos” (apud Morgenhtau, 2003, p. 17). Segundo Weber, "[...] por política entenderemos, consequentemente, o conjunto de esforços feitos com vistas a participar do poder ou a influenciar a divisão do poder, seja entre Estados, seja no interior de um único Estado" (WEBER, 1972, p. 56). Todo político aspira ao poder, quer em função dos fins ou em função do próprio desejo pelo poder e do prestígio que ele confere (Weber, 1972, p. 57). Para esses autores, o poder é definido como o controle do homem sobre a mente e as ações do homem, e a política abrange todas as relações humanas, principalmente, o Estado. 
grupo de representantes do Estado no cenário internacional, especificamente aqueles que falam e negociam em nome desse Estado - diplomatas e chefes de governo (Morgenthau, 2003, p. 199-204). Para o autor, isso se deve ao fato de que mesmo dentro da comunidade nacional, o poder é exercido por um pequeno grupo de cidadãos, e "A grande massa da população se comporta muito mais como objeto do poder do que como seu agente" (Morgenthau, 2003, p. 202). Para ele, o povo raciocina em termos de ganhos imediatos e concepções morais e legais acerca do bem e do mal, e não dispõe de capacidade política e intelectual para representar a nação.

A identificação do indivíduo com o poder nacional é de alguma maneira uma compensação da insatisfação dos desejos individuais no interior da fronteira nacional, é um processo que envolve não apenas a classe média e os funcionários administrativos como também a classe trabalhadora. A isto se acrescenta que a verdadeira natureza da política deve se esconder em justificativas éticas, legais, biológicas e racionalizações ideológicas. Ou seja, o político deve disfarçar a realidade $^{8}$ para que os indivíduos comuns não percebam os interesses de poder que envolvem as escolhas de política externa. E ainda, "O poder, quando dissimulado por ideologias e buscado em nome e para o bem da nação, torna-se um bem para cuja consecução todos os cidadãos devem lutar" (Morgenthau, 2003, p. 203).

Para poder organizar um povo atrás da política externa do governo e arregimentar todas as energias e recursos nacionais em apoio do mesmo, o porta-voz da referida nação, em vez de clamar por mais poder, terá de apelar para necessidades biológicas, como a existência nacional, e para princípios morais, como a justiça (Morgenthau, 2003, p. 178).

Segundo ele, o diplomata precisa avaliar corretamente suas escolhas e se planejar segundo o "interesse nacional” e, ao mesmo tempo, precisa da aprovação popular sobre as suas decisões políticas. A aceitação popular reflete diretamente no moral e no poder da nação perante as demais. O poder nacional é constituído por diversos elementos, entre eles: a geografia, recursos naturais, capacidade industrial, força militar, a índole e o moral nacional. As duas últimas, o moral e a índole nacional, têm um peso decisivo nas escolhas das políticas externas: elas dependem do apoio popular e do envolvimento da sociedade nacional na política

8 Morgenthau utiliza uma citação do marxista Karl Mannheim em uma nota de rodapé na página 173 para definir ideologia enquanto falsa consciência - enganação da realidade. 
internacional. Diferentemente dos demais elementos que configuram o poder nacional, não são fatores materiais que as determinam.

O moral nacional só é colocado à prova em tempos de guerra quando a sobrevivência da nação está em jogo, e ele é rompido, entre outras situações, em função de uma insatisfação popular muito grande em relação ao governo, como o número de perdas humanas em uma guerra. O governante depende da unidade dos grupos nacionais para dar seguimento à sua política externa, quanto mais ligados os indivíduos estiverem com os negócios estrangeiros, melhores condições de elevar o moral nacional são colocadas ao governante. Qualquer país marcado por divisões de classes, raças e etnias terá o seu moral nacional abalado. Ele é o grau de determinação no qual a nação apoia a sua política externa, está imbricado a todas as atividades nacionais. O moral nacional influencia a escolha e a ação da política externa: se uma parcela da população se sente demasiadamente privada dos seus direitos, tenderá a rebaixar o seu moral nacional, e isso dificultará a tomada de decisões do estadista. Portanto, quanto mais ligados os indivíduos estiverem com as ações do seu governo, melhores serão as condições de elevação do moral nacional. Isso deve ser alcançado democraticamente, através da livre interação da população, pois reside na qualidade do governo e na capacidade de representação dos interesses e aspirações do seu povo em matéria de política internacional.

[...] o moral nacional influencia a determinação com a qual o governo põe em prática a sua política externa. Qualquer segmento da população que se sinta privada permanentemente de seus direitos e de participação plena na vida da nação tenderá a ficar com um moral nacional mais baixo e se tornará menos "patriótica" do que aqueles que não padecem da mesma incapacitação. [...] Sempre que divergências profundas dividem um povo, o apoio popular que pode ser angariado em favor de uma política externa será sempre precário. Na realidade, será pequeno mesmo se o sucesso ou fracasso da referida política externa tiver um efeito direto sobre a disputa interna (Morgenthau, 2003, p. 268).

Da mesma forma, a índole nacional está ligada ao poder e ao nacionalismo. A índole nacional corresponde às qualidades vitais e determinantes da nação, aquelas com as quais a nação é reconhecida e lembrada por toda a população mundial. São exemplos de índole nacional, para Morgenthau: a disciplina dos alemães, a iniciativa dos norte-americanos, a força e persistência dos russos, o bom senso dos britânicos e o individualismo dos franceses. 
A índole nacional não pode deixar de ter impacto sobre o poder nacional. Todos os que na guerra e na paz, agem em nome da nação, formulam, executam, ou apoiam as suas políticas; os que elegendo ou sendo eleitos, moldam a opinião pública, produzem e consomem - todos trazem consigo, em maior ou menor grau, a marca dessas qualidades intelectuais e morais que integram a índole nacional. (MORGENTHAU, 2003, p. 259)

Entretanto, o autor adverte que o nacionalismo não pode se tornar um misticismo político. Pois ao colocar à nação a necessidade de um poder para protegê-la e estimular o seu desenvolvimento, a nação passa a precisar do Estado, da mesma forma que o Estado precisa da nação para manter e expandir o seu poder. O ideal do nacionalismo torna-se, portanto, o Estado-nação (MorgenthaU, 2003, p. 311). Para ele, quando o nacionalismo é "sobreinfluenciado" pela índole nacional, resultado de um excesso intelectual e político do sentimento nacional, ele se degenera e acaba se tornando uma religião. Nesse caso, "[...] a comunidade nacional e o Estado se transformam em entidades sobre-humanas, à parte e acima de seus membros individuais, além de credores de lealdade absoluta" (Morgenthau, 2003, p. 311).

A superestima das qualidades de sua própria nação, que é uma das características de todo nacionalismo, faz com que o conceito da raça superior leve a índole nacional até a idolatria. A raça superior, graças à qualidade suprema de sua índole nacional, vê-se destinada a governar o mundo. Em virtude de suas próprias qualidades, ela tem o poder potencial de exercer o domínio sobre todo mundo (Morgenthau, 2003, p. 312).

Em suma, esse nacionalismo exacerbado pode levar a uma política de racismo, sobre a qual a identidade nacional e a sua valoração passam a ser sinônimo de uma raça, e essa raça, identificada como superior às demais raças e nações, como foi, por exemplo, o nazismo. Nesse sentido, vemos que Morgenthau não tem um tratamento acrítico às diferentes formas e usos do nacionalismo, apesar de ter considerado que o binômio Estado-nação poderia ter se tornado obsoleto.

\section{CONSIDERAÇÕES FINAIS}

Ao longo deste artigo buscamos analisar como os estudos realistas de relações internacionais não produziram necessariamente uma disciplina autônoma da ciência política e das ciências sociais. Em A política entre as nações, Hans Morgenthau efetua uma transposição da teoria política clássica e contemporânea 
para o ambiente internacional: o autor pretende entender as relações internacionais a partir de uma comparação com a teoria política clássica. Apesar do Estado-nação ser a categoria analítica fundamental para a teoria realista das relações internacionais, Morgenthau não se preocupou em definir antes o Estado, para então analisar como este atua no cenário internacional; buscou somente entender a função que o Estado exerce dentro das sociedades nacionais para pensar a questão da guerra e da paz internacional. Nesse ponto, os estudos realistas poderiam se fortalecer ao estabelecer um diálogo maior com as teorias sociais contemporâneas, em especial o debate sobre Estado, políticas públicas e a economia política internacional.

A concepção superficial de Estado usada por Morgenthau acabou produzindo nos demais autores da corrente realista uma visão estreita sobre essa categoria. Waltz (1979) chegou a comparar o Estado a uma bola de bilhar, uma estrutura homogênea e maciça. Os realistas tratam a política externa e a política doméstica separadamente, como se a política de defesa, a política industrial e a diplomacia não tivessem relações entre si, não fossem, em alguns casos, um todo contínuo.

Hans Morgenthau não admite a relação entre Estado, nação e capitalismo. A concepção de soberania é apartada da capacidade política, econômica e financeira dos Estados; trata-se de um conceito legal, baseado no direito internacional. Há uma confusão entre a ideia de soberania e a emergência dos Estados e da nação. Segundo ele, o nacionalismo está ligado às guerras napoleônicas, no início do século XIX, e a emergência das soberanias é anterior a esse processo, em meados do século XVI, mas ambas teriam dado origem a uma mesma estrutura, o Estado-nação. Entendemos que Morgenthau não distingue os "tipos" de Estado, por isso, os Estados absolutistas, capitalistas, imperialistas e dependentes recebem o mesmo tratamento. Ademais, ao aceitar que teria se configurado um "nacionalismo universalista" em torno do poder dos Estados Unidos ou que os Estados teriam se tornado obsoletos, dada a interdependência e a vulnerabilidade criadas pelo avanço das armas nucleares durante a Guerra Fria, demonstra a debilidade conceitual dessa categoria de análise.

Para nós, Morgenthau não definiu com clareza o principal objeto de partida do seu estudo da política internacional. Ele se apropria de concepções divergentes entre si. Quando versou sobre a política interna, sobre o Estado nacional, recorreu às concepções pluralistas que defendem os múltiplos pertencimentos e interesses dos indivíduos e grupos dentro da nação e a influência destes grupos nas decisões políticas. Porém, quando versou sobre a política externa, Morgenthau recorreu à concepção elitista, defensora de uma minoria ativa, que dirige uma massa amorfa, uma sociedade divida entre governantes e governados. Além disso, os Estados 
aparecem como entidades soberanas e iguais no cenário internacional mesmo diante das desigualdades internacionais existentes entre Estados dominados (fracos) e Estados imperialistas (potências). Acreditamos que seja importante considerar a relação de poder entre as nações a partir das relações de dominação e desigualdades entre os Estados e tendo como ponto de partida a imbricação entre política doméstica e política externa. Para isso, é preciso se apoiar sobre uma concepção de Estado que trate das múltiplas determinações (econômicas, políticas e sociais), do papel e da função dessa estrutura jurídico-política tanto para a questão nacional como para a política externa. Trata-se de analisar as íntimas e complexas relações entre o cenário nacional e internacional para compreender as relações internacionais.

\section{REFERÊNCIAS BIBLIOGRÁFICAS}

AlgosaibI, Ghazi A. R. The theory of international relations: Hans Morgenthau and his critics. Background, Vol. 8, nº 4, p. 221-256, Feb. 1965.

Aron, Raymond. Paz e Guerra entre as nações. Brasília: Editora Universidade de Brasília, 2001.

GRIFFITHS, Martin. 50 grandes estrategistas das relações internacionais. São Paulo: Editora Contexto, 2004.

HaLlidaY, Fred. Repensando as relações internacionais. Porto Alegre: Ed. UFRGS, 1999. HELLNER, Mark A. The use and abuse of Hobbes: the state of nature in international relations. Polity, Palgrave Macmillan Journals, vol. 13, nº 1, p. 21-31, 1980.

Hoffman, Stanley. "An American social science - international relations". In: LinkLATER, Andrew (editor). International relations: critical concepts in political science. London and New York: Routledge, 2001, p. 77-98.

JACKSON, Patrick Thaddeus. Forum Introduction Is the state a person? Why should we care? Review of International Studies, British International Studies Association, $\mathrm{n}^{\mathrm{o}}$. 30, p. 255-258, 2004.

Maquiavel, Nicolau. O Príncipe. São Paulo: Abril Cultural, 1973.

Morgenthau, Hans J. A política entre as nações - a luta pela poder e pela paz. Brasília: Editora Universidade de Brasília: Imprensa Oficial do Estado de São Paulo: Instituto de Pesquisa de Relações Internacionais, 2003.

Another "great debate": the national interest of the United States. The American Political Science Review, vol. 46, $\mathrm{n}^{0}$ 4, American Political Science Association, p. 961-988, Dec. 1952a.

.What is the national interest of United States? Annals of American Academy of Political and Social Science, vol. 282, p. 1-7, Jul. 1952b. 
Reichwein, Alexander. Rethinking the Roots of Realism: Morgenthau's German Years.

Paper to be presented at the 5oth Annual Convention of the ISA, 15-18 February, New York.

Turner, Stephen. "Morgenthau as a Weberian”. In: Mazur, G. O. (ed.). One Hundred Year Commemoration to the Life of Hans Morgenthau (1904-2004). New York: Semenenko Foundation, 2004.

WALTZ, Kenneth. Theory of international politics. California: Addison-Wesley Publishing Company, 1979.

WEBER, Max. Economia e sociedade: fundamentos da sociologia compreensiva. Volume 2. Brasília, DF: Editora Universidade de Brasília, 1999. Ciência e política - Duas vocações. São Paulo: Cultrix, 1972. 